\title{
Long-Term Enhancement of Neuronal Excitability and Temporal Fidelity Mediated by Metabotropic Glutamate Receptor Subtype 5
}

\author{
Valérie Sourdet, ${ }^{*}$ Michaël Russier, ${ }^{\star}$ Gaël Daoudal, Norbert Ankri, and Dominique Debanne \\ Neurobiologie des Canaux Ioniques, Institut National de la Santé et de la Recherche Médicale Unité Mixte de Recherche 464, Institut Fédératif de Recherche \\ Jean Roche, Université de la Méditerranée, F-13916 Marseille Cedex 20, France
}

\begin{abstract}
The cellular substrate for memory is generally attributed to long-lasting changes in synaptic strength. We report here that synaptic or pharmacological activation of the metabotropic glutamate receptor subtype 5 (mGluR5) induces long-term potentiation of intrinsic excitability (LTP-IE) in layer V pyramidal neurons. mGluR5-dependent LTP-IE was associated with a persistent reduction of the afterhyperpolarization (AHP) outward current $\left(I_{\mathrm{AHP}}\right)$, resulting in the potentiation of EPSP-spike coupling. Apamin occluded induction of LTP-IE, indicating that downregulation of small conductance calcium-dependent potassium (SK) channels mediates this process. In addition to the improved reliability of the input- output function, LTP-IE led to increased temporal precision. The induced reduction of $I_{\mathrm{AHP}}$ accelerated the rate of membrane depolarization preceding each action potential and subsequently decreased the jitter of the neuronal discharge. We conclude that mGluR5-dependent LTP-IE not only promotes the spread of excitation in the cortical network but also persistently enhances the temporal fidelity of the neuronal message.
\end{abstract}

Key words: long-term potentiation; neocortex; excitability; temporal precision; mGluR5; reliability

\section{Introduction}

A remarkable property of many synapses in the CNS is their ability to undergo activity-dependent, long-lasting bi-directional changes in synaptic strength, referred to as long-term potentiation (LTP) and long-term depression (LTD), two processes that may underlie certain forms of memory (Bliss and Collingridge, 1993; Sourdet and Debanne, 1999; Abbott and Nelson, 2000). The induction of these types of plasticity has been found to depend on NMDA receptor (NMDAR) or metabotropic glutamate receptor (mGluR) activation (Bliss and Collingridge, 1993; Bortolotto et al., 1994). In parallel with plasticity of synaptic strength, synaptic activation of NMDAR results in the induction of a longlasting increase in neuronal excitability in cerebellar (Aizenman and Linden, 2000; Armano et al., 2000) and hippocampal neurons (Ganguly et al., 2000; Daoudal et al., 2002). This plasticity, which affects the input-output relation of the neuron and the spike threshold, may functionally and synergistically complement synaptic plasticity contributing to the formation of a coher-

\footnotetext{
Received July 30, 2003; revised Sept. 22, 2003; accepted Sept. 22, 2003.

This work was supported by the Centre National de la Recherche Scientifique, Ministry of Research (Actions Concertées Incitatives "Jeunes Chercheurs" 5169), Institut National de la Santé et de la Recherche Médicale (Programme "Avenir"), and Fondation pour la Recherche Médicale. We thank L. Fronzaroli for excellent technical assistance and Dr. M. Seagar for his constant support. We thank Dr. U. Gerber, Dr. P. Pedarzani, Prof. M. Scanziani, Dr. M. Seagar, and Dr. G. G. Turrigiano for constructive criticisms on this manuscript.

*V.S. and M.R. contributed equally to this work.

Correspondence should be addressed to Dr. D. Debanne, Neurobiologie des Canaux Ioniques, Institut National de la Santé et de la Recherche Médicale Unité Mixte de Recherche 464, Institut Fédératif de Recherche Jean Roche, Faculté de Médecine Secteur Nord, Boulevard Pierre Dramard, F-13916 Marseille Cedex 20, France. E-mail: debanne.d@jean-roche.univ-mrs.fr.

Copyright $\odot 2003$ Society for Neuroscience 0270-6474/03/2310238-11\$15.00/0
}

ent cortical engram. Pharmacological stimulation of mGluRs may lead to a sustained enhancement of intrinsic excitability in hippocampal neurons (Cohen et al., 1999; Ireland and Abraham, 2002), but it is not clear whether synaptic activation of mGluR can initiate long-lasting plasticity in neuronal excitability.

We have examined here the long-term effects of mGluR stimulation on the intrinsic excitability of neocortical neurons. We show that the synaptic or pharmacological activation of mGluR5 induces a long-lasting ( $>25-60 \mathrm{~min}$ ) enhancement of the number of action potentials (APs) elicited by current injection or by dendritic EPSPs in layer $\mathrm{V}$ pyramidal neurons. The induction of LTP of intrinsic excitability (LTP-IE) was found to require the conjunction of postsynaptic depolarization and the stimulation of mGluRs, indicating that active neurons in the cortex will express LTP-IE. LTP-IE was associated with a lasting reduction of $I_{\mathrm{AHP}}$ and was occluded when synaptic stimulation was applied in the presence of the small conductance calcium-dependent potassium (SK) channel blocker apamin. In addition, after induction of LTP-IE, the temporal jitter of spike discharge was reduced, whereas the reliability of the spike train was persistently enhanced. We therefore conclude that the synaptic activation of mGluR5 not only facilitates the spread of excitation in the cortex but may also modify temporal coding in single neurons.

\section{Materials and Methods}

Whole-cell patch clamp. Cortical slices $(350 \mu \mathrm{m})$ were obtained from postnatal day 11-16 rats according to the institutional guidelines. Slices were cut in an ice-cold solution containing (in mM): 280 sucrose, 26 $\mathrm{NaHCO}_{3}, 10$ D-glucose, $10 \mathrm{MgCl}_{2}, 1.3 \mathrm{KCl}, 1 \mathrm{CaCl}_{2}$, and were bubbled with $95 \% \mathrm{O}_{2} / 5 \% \mathrm{CO}_{2}, \mathrm{pH}$ 7.4. Slices recovered $(1 \mathrm{hr})$ in a solution 
containing (in mM): $125 \mathrm{NaCl}, 26 \mathrm{NaHCO}_{3}, 3 \mathrm{CaCl}_{2}, 2.5 \mathrm{KCl}, 2 \mathrm{MgCl}_{2}$, $0.8 \mathrm{NaH}_{2} \mathrm{PO}_{4}, 10$ D-glucose, and were equilibrated with $95 \% \mathrm{O}_{2} / 5 \% \mathrm{CO}_{2}$. Each slice was transferred to a submerged chamber mounted on an upright microscope. Layer V pyramidal neurons were visualized using DIC infrared videomicroscopy. Neurons were occasionally labeled with biocytin $(0.3 \%)$ and revealed with DAB. Whole-cell recordings were made at room temperature $\left(22-24^{\circ} \mathrm{C}\right)$ except when EPSPs were evoked by stimulation in the layer II/III $\left[34^{\circ} \mathrm{C}\right.$ in temperature-controlled recording chamber (Luigs and Neumann, Ratingen, Germany)]. Patch pipettes (10-15 $\mathrm{M} \Omega$ ) were filled with a solution containing (in $\mathrm{mM}$ ): 120 K-gluconate, $20 \mathrm{KCl}, 10 \mathrm{HEPES}, 0.5-10$ EGTA, $2 \mathrm{Na}_{2} \mathrm{ATP}, 0.3 \mathrm{NaGTP}$, and $2 \mathrm{MgCl}_{2}, \mathrm{pH}$ 7.4. The relatively high concentration of EGTA allowed
A

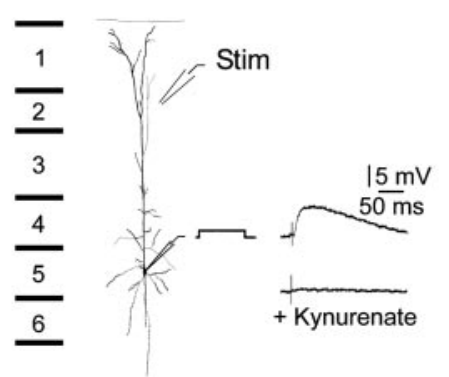

B

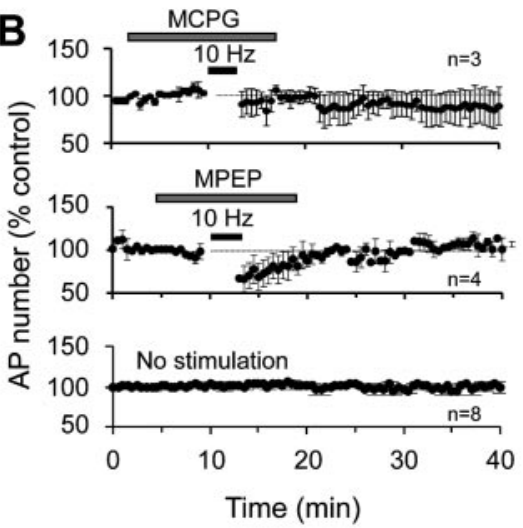

D

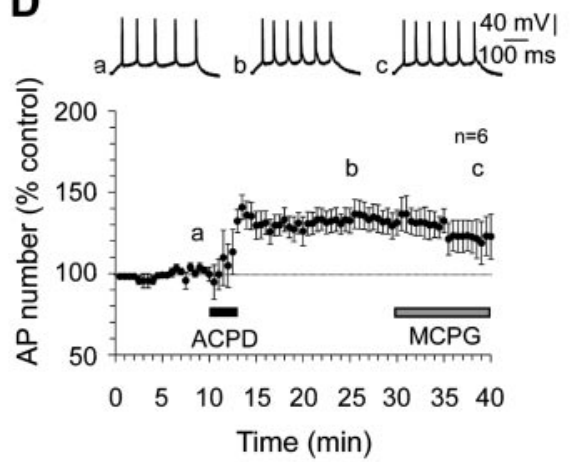

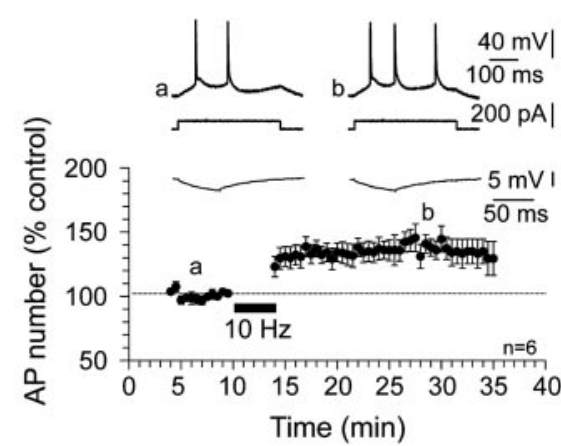

C
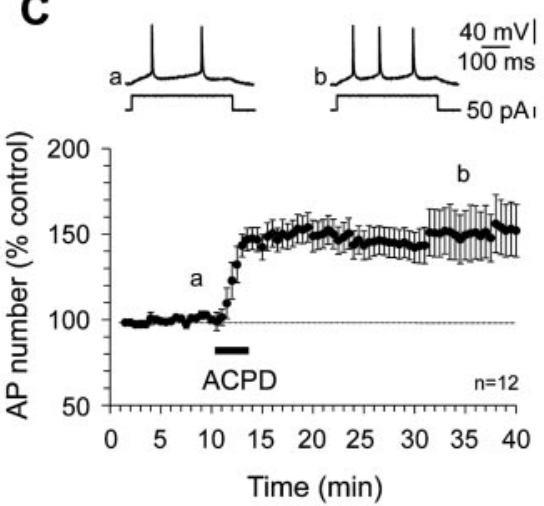

E

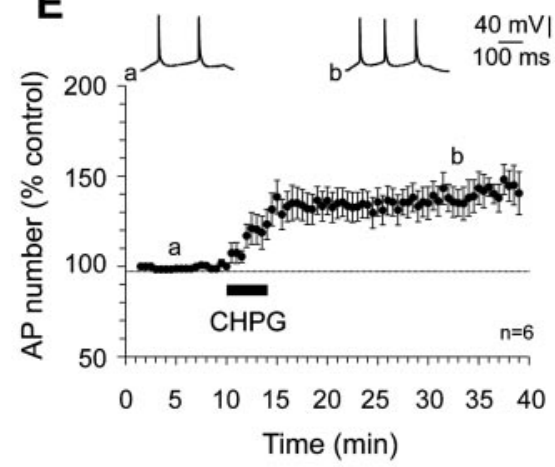

Figure 1. Synaptic or pharmacological induction of mGluR-dependent LTP-IE in layer V pyramidal neurons. A, LTP-IE was induced by tetanic stimulation of glutamatergic synaptic inputs at $10 \mathrm{~Hz}$ in the presence of ionotropic receptor antagonists. Under these conditions, the stimulation had no visible effect on the membrane potential of the recorded neuron. Left, Recording setup and morphology of a camera lucida reconstructed postnatal day 15 neuron filled with biocytin. EPSP was evoked by stimulation in layer II/III. The presence of a large EPSP (5-12 mV) was assessed before application of the ionotropic receptor antagonists kynurenate (2 mm) and picrotoxin (100 $\mu \mathrm{m})$. Right, Number of APs evoked by a constant current pulse before and after tetanic stimulation. Top traces (a and b) show before and $25 \mathrm{~min}$ after $10 \mathrm{~Hz}$ stimulation. No change in input resistance tested with hyperpolarizing pulses was observed. $B$, Top, Normalized change in the AP number induced by synaptic stimulation ( $10 \mathrm{~Hz})$ in the presence of $1 \mathrm{~mm} \mathrm{MCPG}$. Middle, Normalized change in AP number after $10 \mathrm{~Hz}$ stimulation in the presence of $100 \mu \mathrm{M}$ MPEP. Bottom, Temporal stability of spike number in the absence of any synaptic stimulation. $C$, Time course of the modification in intrinsic excitability induced by $50 \mu \mathrm{M}(\mathrm{O})$ ACPD. D, MCPG (1 mM) does not affect LTP-IE expression. E, Induction of LTP-IE by $100-200 \mu \mathrm{M}(\mathrm{O})$ CHPG. Top traces (a and b) show before and 25 min after application of $100 \mu \mathrm{M}$ CHPG. us to isolate the medium afterhyperpolarization (AHP) by the selective blockade of the slow AHP (Storm, 1987). Some experiments were per$(\mathrm{mAHP})(n=2)$, and ramp experiments $(n=3)]$. LTP-IE was indistinthe pooled together. Control recordings were performed $\mathrm{mM}$ ) in the pipette. Recordings were made with appropriate bridge and capacitance compensation (series resistance 20-50 M 2 ). Recordings were stabilized for at least $10 \mathrm{~min}$ after breaking-in and before testing the excitability of the neuron.

Stimulation, data acquisition, and analysis. EPSPs were evoked with $100-150 \mu$ sec stimuli through glass electrodes filled with extracellular saline. LTP-IE was induced synaptically with bursts of 10 shocks at $10 \mathrm{~Hz}$ delivered at a rate of $0.3 \mathrm{~Hz}$ during 3-4 min. This protocol was referred to as $10 \mathrm{~Hz}$ tetanus. Analog signals were low-pass filtered $(3 \mathrm{kHz})$, and acquisition of $500 \mathrm{msec}$ sequences was performed at $12 \mathrm{kHz}$. Membrane potential was held at a constant value, and trials with fluctuation more than 1 $\mathrm{mV}$ were discarded. Pooled normalized data were expressed as means \pm SEM, and statistical significance was accepted at the $p<0.05$ level with the Mann-Whitney $U$ test.

All drugs were bath applied. $1 S, 3 R$-aminocyclopentane-1,3-dicarboxylate $(1 S, 3 R$ ACPD), D(-)-2-amino-5-phosphonopentanoic acid (D-AP5), 2-methyl-6-(phenylethynyl)pyridine (MPEPhydrochloride), $(R, S)$-2-chloro-5hydroxyphenylglycine (CHPG), $R, S$ - $\alpha$-methyl4-carboxyphenylglycine ( $R, S-\mathrm{MCPG})$, and 1-ethyl-2-benzimidazolinone (EBIO) were purchased from Tocris Cookson. Apamin was obtained from Alomone Labs.

Dynamic clamp and analysis. A burst of 32 AMPA-like EPSPs (mean frequency, $40 \mathrm{~Hz}$ ) was simulated by a dynamic-clamp amplifier (SM1; Cambridge Conductance, Cambridge, $\mathrm{UK})\left(E_{\mathrm{rev}}=0 \mathrm{mV}\right)$ fed by a digital-analog converter (UEIdaq board) and driven by a personal computer (Detectivent; N. Ankri). The conductance profile of each EPSC was determined by two exponentials (EPSC-rise time $=1.5 \mathrm{msec}$ and $\tau_{\text {decay }}=10$ msec; Detectivent, LabView) and matched the kinetics of experimentally determined mEPSCs $(1.3 \pm 0.2 \mathrm{msec}$; $\tau_{\text {decay }}=9 \pm 3 \mathrm{msec} ; n=3$ cells $)$. The temporal pattern of the burst of EPSPs was randomly determined, but the selected pattern was presented at $4 \mathrm{sec}$ intervals with constant parameters throughout the whole experiment. Reliability was defined as the proportion of all spikes that were repeatable (Harsch and Robinson, 2000) and was calculated as the number of spikes normalized to the number of trials in a defined time window (usually a bin of $10 \mathrm{msec}$ ). This ratio was then averaged over the whole stimulation period. The temporal jitter was calculated as the deviation to the median of the spike latency. A log-ANOVA test was applied to test the significance of the modification of the jitter. This test was found to be better adapted than the $F$-test because of its lower sensitivity to deviation in nonGaussian distributions. 


\section{Results}

\section{Synaptic and pharmacological induction of} mGluR5-dependent LTP-IE

Layer $\mathrm{V}$ pyramidal neurons from the rat sensorimotor cortex were recorded in the whole-cell configuration. Tetanic stimulation of layer II/III glutamatergic inputs at $10 \mathrm{~Hz}$ for 3-4 min in the presence of the ionotropic receptor antagonists kynurenate and picrotoxin increased neuronal excitability. This potentiation was characterized by a rapid and persistent increase in the number of APs elicited by a current pulse of constant amplitude and thus was referred to as synaptically induced LTP-IE (sLTP-IE). Twenty-five minutes after synaptic stimulation, sLTP-IE amounted to $140 \pm 7 \%$ of the control $(n=6)$ (Fig. $1 A, B)$. The input resistance and the holding current required to maintain a constant membrane potential $( \pm 1 \mathrm{mV})$ remained unchanged after induction of sLTP-IE $(168 \pm 35$ and $159 \pm 47 \mathrm{M} \Omega ; n=6)$ (Fig. $1 A)(-1 \pm 0.5$ and $3 \pm 0.3 \mathrm{pA} ; n=6$; data not shown). Because AMPA, NMDA, and kainate receptors were blocked by kynurenate, sLTP-IE induction might have been mediated by mGluRs. Indeed, when the mGluR antagonist RS-MCPG was added to the external medium (in the presence of kynurenate and picrotoxin), tetanic stimulation no longer induced sLTP-IE $(90 \pm 15 \% ; n=5)$ (Fig. $1 B)$. Furthermore, no change in the number of APs elicited by a constant current pulse was observed $20-25 \mathrm{~min}$ after control stimulation $(98 \pm 3 \% ; n=8)($ Fig. $1 B)$, indicating that sLTP-IE induction requires mGluR activation. The induction of sLTP-IE was blocked when the pipette contained 10 mм BAPTA (106 $\pm 6 \%$; $n=3$; data not shown), indicating that a postsynaptic rise in calcium is required.

To further evaluate the role of mGluRs, tetanus was replaced by a brief application of selective mGluR agonists. Pharmacologically induced LTP-IE (pLTP-IE) was induced by bath application of $50 \mu \mathrm{M} 1 S, 3 R$-ACPD (potentiation measured at $+25 \mathrm{~min}$; $148 \pm 7 \% ; n=12$ ) (Fig. 1C). Similar results were obtained with $100 \mu \mathrm{M}$ ACPD (155 $\pm 4 \% ; n=8)$. The potentiation induced by 50-100 $\mu \mathrm{M}$ ACPD was extremely stable and persisted for as long as the recording could be maintained ( $>60 \mathrm{~min})$. The input resistance was not significantly affected after induction of pLTP-IE by $50-100 \mu \mathrm{M}$ ACPD $(115 \pm 27$ and $127 \pm 39 \mathrm{M} \Omega ; n=6$; data not shown), indicating that mGluR-induced LTP-IE is not associated with any change in the passive properties of the neuron. The holding current necessary to maintain a constant membrane potential $( \pm 1 \mathrm{mV})$ was changed significantly during the application of 50-100 $\mu \mathrm{M}$ ACPD but not in the long term $(\Delta I=-36 \pm$ $5 \mathrm{pA}, n=16$, and $-11 \pm 11 \mathrm{pA}, n=16$, respectively; data not shown). Potentiation was blocked by the antagonist MCPG (1 $\mathrm{mM})$, which prevented the increase in spike number (103 $\pm 3 \%$; $n=6$; data not shown) induced by $50 \mu \mathrm{M}$ ACPD. In acute brain slices, agonist washout is generally slow, which may account for some lasting effects; MCPG therefore was applied $15 \mathrm{~min}$ after establishment of sustained potentiation. No significant decrement in the induced pLTP-IE was observed in the presence of MCPG $(p>0.05)$ (Fig. 1D). These data show that mGluR activation is necessary for the induction but not the expression of pLTP-IE.

In layer $\mathrm{V}$ pyramidal neurons, mGluR5 is mainly located postsynaptically (Munoz et al., 1999). We therefore tested whether LTP-IE was also induced by activation of mGluR5 in the presence of kynurenate and picrotoxin. The application of the mGluR5 agonist CHPG $(100-200 \mu \mathrm{M})$ induced a stable pLTP-IE $(137 \pm 8 \% ; n=6)$ (Fig. $1 E)$. In the presence of the mGluR5 antagonist MPEP (5-100 $\mu \mathrm{M})$ (Gasparini et al., 1999), $50 \mu \mathrm{M}$

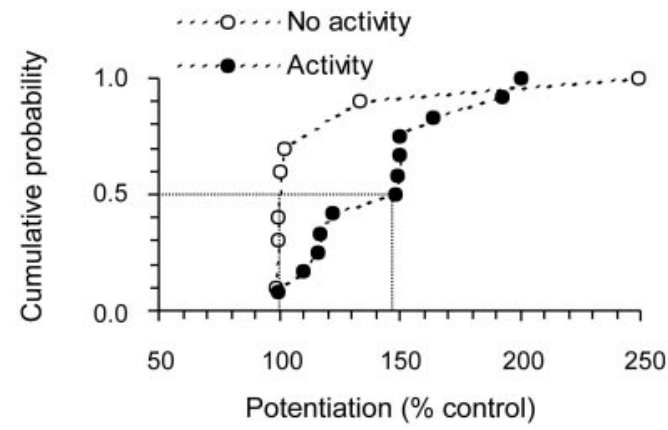

Figure 2. Associative properties of LTP-IE. Cumulative probability of pLTP-IE induced by 50 $\mu M A C P D$ with $(O)$ or without $(\bigcirc)$ postsynaptic spiking activity $(p>0.05)$ is shown.

ACPD did not produce significant pLTP-IE (111 $\pm 7 \%$; $n=6$; data not shown). Finally, tetanic stimulation of a glutamatergic input in the presence of MPEP $(100 \mu \mathrm{M})$, kynurenate, and picrotoxin did not induce sLTP-IE $(103 \pm 5 \% ; n=4)$ (Fig. $1 B$ ). Interestingly, pLTP-IE induced by $200 \mu \mathrm{M}$ CHPG occluded the subsequent induction of sLTP-IE by $10 \mathrm{~Hz}$ stimulation (118 $5 \% ; n=4$ after CHPG and $119 \pm 9 \%$ after $10 \mathrm{~Hz} ; n=4$; data not shown), indicating that both protocols lead to identical regulation of intrinsic excitability. We conclude that synaptic activation of mGluR5 induced LTP-IE in layer V pyramidal neurons.

\section{Associative property of LTP-IE}

Certain forms of synaptic plasticity require the coactivation of synaptic receptors and postsynaptic APs (Magee and Johnston, 1997; Sourdet and Debanne, 1999). We therefore examined whether postsynaptic firing was also necessary for LTP-IE induction. The firing of the neuron was interrupted during and $7 \mathrm{~min}$ after the end of ACPD application by switching off the current pulse. In the absence of postsynaptic APs, the proportion of neurons expressing pLTP-IE $>110 \%$ was lower ( 2 of 7 ) than in previous experiments in which postsynaptic firing was maintained during mGluR stimulation (11 of 12 ; Mann-Whitney $U, p<$ 0.05 ) (Fig. 2). We conclude that mGluR-induced LTP-IE is associative and will preferentially affect active cortical neurons.

\section{Long-lasting reduction of $I_{\mathrm{AHP}}$ by mGluR}

Long-lasting depression of the AHP has been reported in hippocampal and neocortical neurons after specific learning tasks (Disterhoft et al., 1986; Moyer et al., 1996; Saar et al., 1998). In layer V pyramidal neurons, the AHP current has two main components that can be distinguished by their pharmacology and kinetics: slow $I_{\mathrm{AHP}}\left(\mathrm{sI}_{\mathrm{AHP}}\right)$ and $I_{\mathrm{AHP}} \cdot \mathrm{sI}_{\mathrm{AHP}}$ is insensitive to apamin and highly regulated by several neurotransmitters, including glutamate, through the activation of mGluR (Charpak et al., 1990; Mannaioni et al., 2001). The $I_{\mathrm{AHP}}$ current mediates part of the mAHP through the activation of SK1 and SK2 subtypes and is highly sensitive to apamin; however, its modulation by neurotransmitters is less clear. A long-lasting reduction of both mAHP and sAHP has been reported after activation of group I mGluRs in hippocampal cells (Ireland and Abraham, 2002). It is not clear, however, whether this is a real reduction in the mAHP because the two AHPs display a partial overlap. In our study, we pharmacologically isolated the $I_{\mathrm{AHP}}$ current that is highly expressed in layer 5 pyramidal neurons (Stocker and Pedarzani, 2000) by a slow calcium buffer (10 mM EGTA) in the patch pipette. EGTA induced a fast rundown of $s I_{\mathrm{AHP}}$ but left $I_{\mathrm{AHP}}$ unchanged, as observed previously in CA1 pyramidal cells $(n=3$; data not 

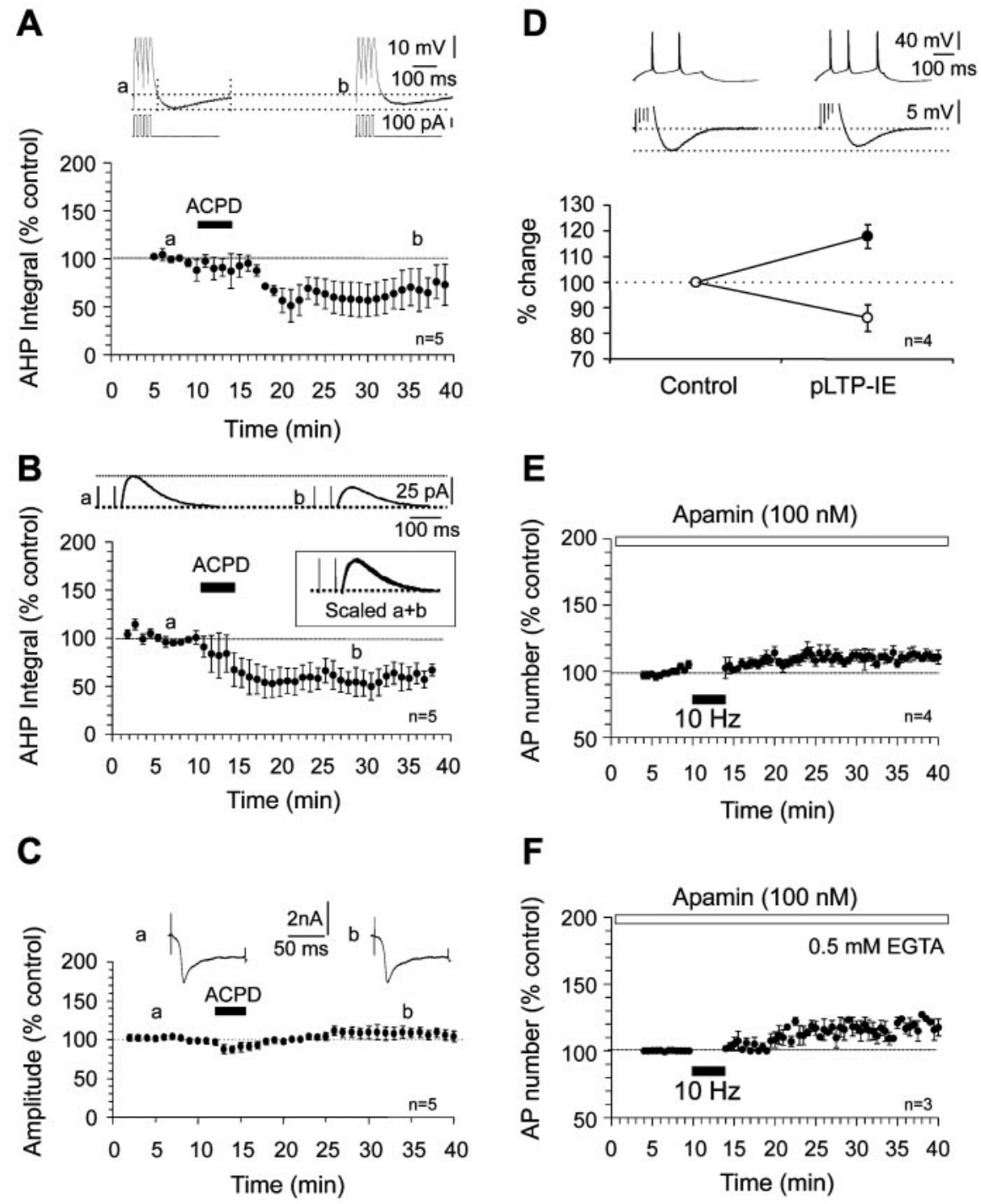

Figure 3. LTP-IE induced by mGluR activation is associated with a reduction of $m A H P$ and $I_{\text {AHP. }}$. $A$, Time course of the normalized AHP integral after stimulation of mGluRs with ACPD $(50-100 \mu \mathrm{M})$. For each AHP in response to a train of four APs, the voltage trace was integrated, relative to a horizontal baseline cursor, for an interval of $300 \mathrm{msec}$ (dotted lines). B, Time course of the depression of the normalized $I_{\text {AHP }}$ integral by 50-100 $\mu \mathrm{MACPD}$. The experiment was performed in the presence of $1 \mu \mathrm{m}$ TTX and $5 \mathrm{mM}$ TEA. For each AHP current, in response to a postsynaptic depolarization to $+10 \mathrm{mV}$, the current trace was integrated relative to a horizontal baseline cursor for an interval of $300 \mathrm{msec}$. Inset, Scaled mAHPs before and after ACPD (Scaled a +b). C, Time course of the calcium current amplitude in the experiment shown in $B$. The calcium current evoked by a step to $+10 \mathrm{mV}$ was recorded in the presence of $1 \mu \mathrm{M}$ TTX, $1 \mathrm{~mm}$ 4-AP, and 5-30 mM TEA. The peak amplitude of the inward current was measured by subtracting the leak and capacitive currents. Calcium current before $(a)$ and 25 min after $(b)$ application of ACPD. D, pLTP-IE with a concomitant depression of the AHP in the same neurons. Normalized changes of the spike number $(\bigcirc)$ and AHP integral $(\bigcirc) 25$ min after CHPG application $(n=4)$. Top traces, Increase in the spike number and reduction of the AHP evoked by four APs in a representative neuron. $E$, Normalized AP number after $10 \mathrm{~Hz}$ stimulation in the presence of apamin (10 mm EGTA). F, Normalized AP number after $10 \mathrm{~Hz}$ stimulation in the presence of apamin ( $0.5 \mathrm{~mm}$ EGTA).

shown) (Storm, 1987). The remaining current was insensitive to $5 \mathrm{~mm}$ tetraethylammonium (TEA) but was fully blocked by 250 $\mu \mathrm{M}$ cadmium, indicating that it was mediated by SK channels. In addition, the $\mathrm{mAHP}$ recorded with pipettes containing $10 \mathrm{~mm}$ EGTA was strongly reduced by apamin $(n=3)$.

We therefore determined the integral of the mAHP and $I_{\mathrm{AHP}}$ after induction of pLTP-IE (Fig. 3A,B). The integral of the mAHP evoked by a train of four APs was depressed 20 min after induction of pLTP-IE with ACPD (61 $\pm 17 \%$ of the control; $n=5)$ (Fig. $3 A$ ). In these conditions, special care was taken to elicit four spikes in control and after LTP-IE induction. Traces that spuri- ously contained three or five APs were discarded from the analysis. No change in the mAHP was observed in neurons that were not stimulated by mGluR agonists ( $103 \pm$ $10 \% ; n=6$; data not shown). In a second set of experiments, $I_{\mathrm{AHP}}$ was isolated in the presence of $1 \mu \mathrm{M}$ TTX and $5 \mathrm{~mm}$ TEA by voltage clamping the neuron near -55 $\mathrm{mV}$ and depolarizing the membrane to $+10 \mathrm{mV}$. The application of 50-100 $\mu \mathrm{M}$ ACPD induced a stable depression of $I_{\mathrm{AHP}}$ current $(52 \pm 13 \% ; n=5)$ (Fig. $3 B$ ). The amplitude of the inward calcium current generated by the postsynaptic depolarization was slightly depressed by ACPD but was found to remain unchanged in the long term (110 $\pm 5 \% ; n=5)$ (Fig. $3 C$ ). These data indicate that the induction of LTP-IE is mediated by a direct postsynaptic action of mGluR. Importantly, pLTP-IE induced with CHPG (118 $\pm 5 \%$; $n=4)$ and a decrease in the AHP integral evoked by four APs ( $86 \pm 5 \% ; n=4$ ) (Fig. $3 D$ ) occurred in parallel in the same neurons, indicating that the events were linked. We conclude that a long-lasting depression of the $I_{\mathrm{AHP}}$ current is associated with the expression of pLTP-IE.

Because the reduction of $I_{\mathrm{AHP}}$ was persistently diminished after stimulation of mGluRs, we tested whether the pharmacological blockade of SK channels with apamin occluded sLTP-IE. These experiments were performed with pipettes containing $10 \mathrm{mM}$ EGTA. The amount of sLTP-IE was found to be significantly reduced when the $10 \mathrm{~Hz}$ tetanus was delivered in the presence of $\operatorname{apamin}(100 \mathrm{nM})(110 \pm 3 \%, n=4$ vs $140 \pm$ $7, n=6$ without apamin; Mann-Whitney $U, p<0.05$ ) (Fig. 3E). Thus, we conclude that sLTP-IE is largely mediated by the downregulation of SK channels.

Are other channels also involved in the expression of sLTP-IE? To test this hypothesis we measured LTP-IE induced when the intracellular calcium concentration was not buffered ( $0.5 \mathrm{~mm}$ EGTA) but in the presence of apamin (100 nM). Under these conditions, the $10 \mathrm{~Hz}$ tetanus induced a small LTP-IE $(116 \pm 6 \% ; n=3)$ (Fig. $3 F$ ). These data suggest that other currents (possibly $s I_{\mathrm{AHP}}$ that was not blocked in these experiments) might also participate in the expression of sLTP-IE.

The recordings reported so far were obtained with K-gluconate in the patch pipette; however, gluconate may interfere with slow and medium AHPs (Velumian et al., 1997). We performed additional experiments with $\mathrm{K}-\mathrm{MeSO}_{4}$ in the patch pipette, a solution that has little effect on both $\mathrm{s}_{\mathrm{AHP}}$ and $I_{\mathrm{AHP}}$. $\mathrm{SLTP}$-IE was reliably induced by the $10 \mathrm{~Hz}$ stimulation when $\mathrm{K}-\mathrm{MeSO}_{4}$ was substituted for K-gluconate ( $145 \pm 17 \% ; n=4$; data not shown). We conclude that the recording conditions do not strongly determine the induction of LTP-IE. 
A
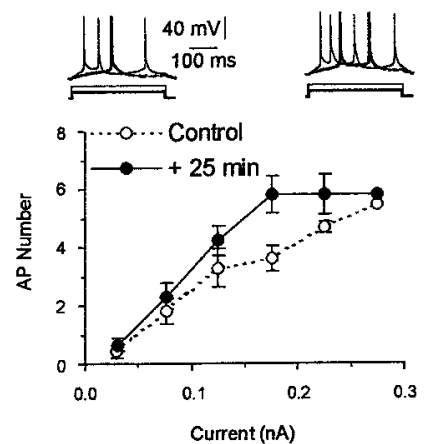

B

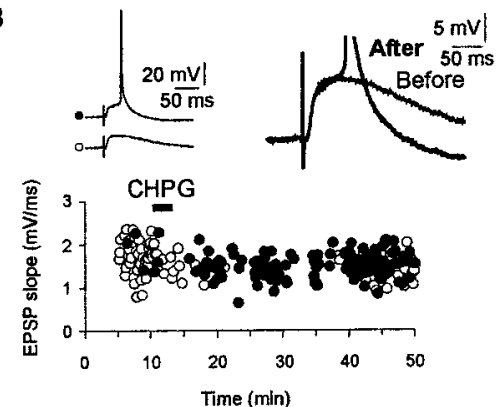

C

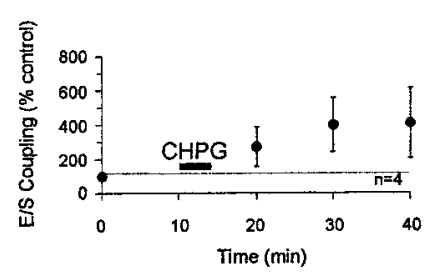

Figure 4. LTP-IE enhances the input- output function of the neuron. $A$, Before and $25 \mathrm{~min}$ after the application of ACPD, the excitability of the neuron was tested with 5-10 pulses of varying intensity. Note that for each current level the number of APs was significantly potentiated. Top traces, Before (left) and after (right) induction of LTP-IE. B, Long-lasting potentiation of EPSP-spike coupling induced by CHPG. EPSP slope versus time $(\bigcirc$, subthreshold EPSPs; suprathreshold EPSPS). Right inset, EPSPs of a given slope before and after induction of LTP-IE. C, Time course of the potentiation of the normalized EPSP-spike coupling induced by CHPG $(100-200 \mu \mathrm{m} ; n=4)$.

\section{Enhanced input-output function}

In the above experiments, pLTP-IE was quantified using stimulation that evoked two to three APs. We determined whether the increase in excitability was also observed over a range of neuronal excitation. The input-output function was assessed with progressively increasing current steps (10-20 pA) before and 20-25 min after mGluR stimulation. The number of APs elicited by any given current was increased after induction of pLTP-IE (Fig. $4 A$ ). The current necessary to elicit a single AP was reduced by $30 \pm$ $5 \%(n=6$; data not shown), suggesting that an EPSP that was just subthreshold could become an efficient input after pLTP-IE induction. Thus, the input-output function of the neuron was assessed with evoked dendritic EPSPs adjusted to be just subthreshold for spike generation ( $\sim 30 \%$ of APs in control). Experiments were performed in the presence of D-AP5 $(50 \mu \mathrm{M})$ to block NMDARs, and pLTP-IE was induced with 100-200 $\mu \mathrm{M}$ CHPG. After washout of CHPG, the EPSP slope was not potentiated (91 $\pm 4 \% ; n=4)$, but EPSPs consistently elicited postsynaptic APs (Fig. $4 B$ ), indicating that pLTP-IE promotes the spread of excitation in the cortex. On average, the probability of eliciting an AP was enhanced to $398 \pm 157 \%$ of the control, $20-25$ min after the application of CHPG $(n=4)$ (Fig. $4 C$ ).
Enhanced reliability and temporal precision of the spike train One of the main roles of cortical neurons is to transform an input into a reliable output (Mainen and Sejnowski, 1995). The reliability and precision of the spike train are two temporal parameters that are fundamental for neuronal coding and plasticity. For instance, the temporal coincidence of presynaptic and postsynaptic spikes determines synaptic strength with a millisecond accuracy (Markram et al., 1997; Bi and Poo, 1998; Debanne et al., 1998). Synaptically induced long-term regulation of the reliability and temporal precision of spike trains has never been reported; however, because of the persistent regulation of intrinsic currents involved in spike discharge, we investigated the consequences of LTP-IE on the temporal structure of neuronal firing.

We first determined whether the reliability of the spike train was changed after induction of pLTP-IE. Reliability was assessed with a barrage of EPSPs simulated with the dynamic-clamp technique (Sharp et al., 1993). All experiments were performed in the presence of kynurenate and picrotoxin. Before pLTP-IE, the burst of EPSPs evoked on average two to three APs that showed occasional failures and considerable temporal fluctuations from trial to trial (Fig. $5 A, B$ ). Forty minutes after mGluR stimulation by $\mathrm{CHPG}$, the barrage of simulated EPSPs evoked twice as many APs $(191 \pm 32 \% ; n=4)$ (Fig. $5 A, B)$. In addition to a decrease in the jitter of late APs (Fig. $5 B$ ), the reliability index was increased after induction of pLTP-IE $(0.40 \pm 0.08$ in control vs $0.72 \pm 0.07$, 35 min after mGluR5 stimulation; $n=4$ ) (Fig. 5C). We conclude that the reliability of neuronal discharge is persistently increased after a brief episode of mGluR5 stimulation.

This increase in reliability was observed principally for late and just suprathreshold modulation of the input signal. In particular, late APs exhibited a reduced jitter in their latency after induction of LTP-IE (Fig. 5B). We therefore examined whether the temporal precision of neuron discharge improved after induction of LTP-IE. The change in the precision of spike discharge was analyzed after synaptic and pharmacological induction of LTP-IE. We first tested whether the temporal precision of the second spike was modified by pLTP-IE when the neuron was stimulated by a barrage of simulated EPSPs. As illustrated in Figure $6 \mathrm{~A}$, the jitter of the second spike was considerably reduced 35 min after induction of pLTP-IE with CHPG ( $45 \pm 8 \%$ of the control; $n=3$ cells).

When a pattern of simulated EPSPs was used, APs were preferentially elicited at depolarization maxima. Thus, peaks in the pattern of simulated EPSPs can be considered as local attractors that may introduce a bias in the temporal distribution of the APs. Then we analyzed the temporal precision of the discharge produced by current pulses of long duration, before and after induction of sLTP-IE. The temporal jitter of the second AP was significantly decreased after induction of SLTP-IE by $10 \mathrm{~Hz}$ stimulation $(\mathrm{SD}=14.9 \mathrm{msec}$ in control and $\mathrm{SD}=9.6 \mathrm{msec}$ after sLTP-IE; $n=$ 6; $\log$-ANOVA test, $p<0.05$ ) (Fig. $6 B, C$ ). A similar increase in temporal precision was also observed when pLTP-IE was induced with $\mathrm{CHPG}(\mathrm{SD}=16.4 \mathrm{msec}$ in control and $\mathrm{SD}=12.1 \mathrm{msec}$ after LTP-IE induction; $n=6 ; p<0.05$; data not shown). Finally, the variability remained unchanged in control experiments $(\mathrm{SD}=$ $17.0 \mathrm{msec}$ and $\mathrm{SD}=17.8 \mathrm{msec}$ before and $+25 \mathrm{~min}$, respectively; $n=6 ; p>0.05$ ) (Fig. 6D). We conclude that induction of mGluR5-dependent LTP-IE is specifically associated with a high precision of spike discharge.

\section{Role of mAHP in the jitter of the neuronal discharge}

Because $I_{\mathrm{AHP}}$ was found to be depressed by mGluR activation, the reduced jitter might result directly from a downregulation of SK 

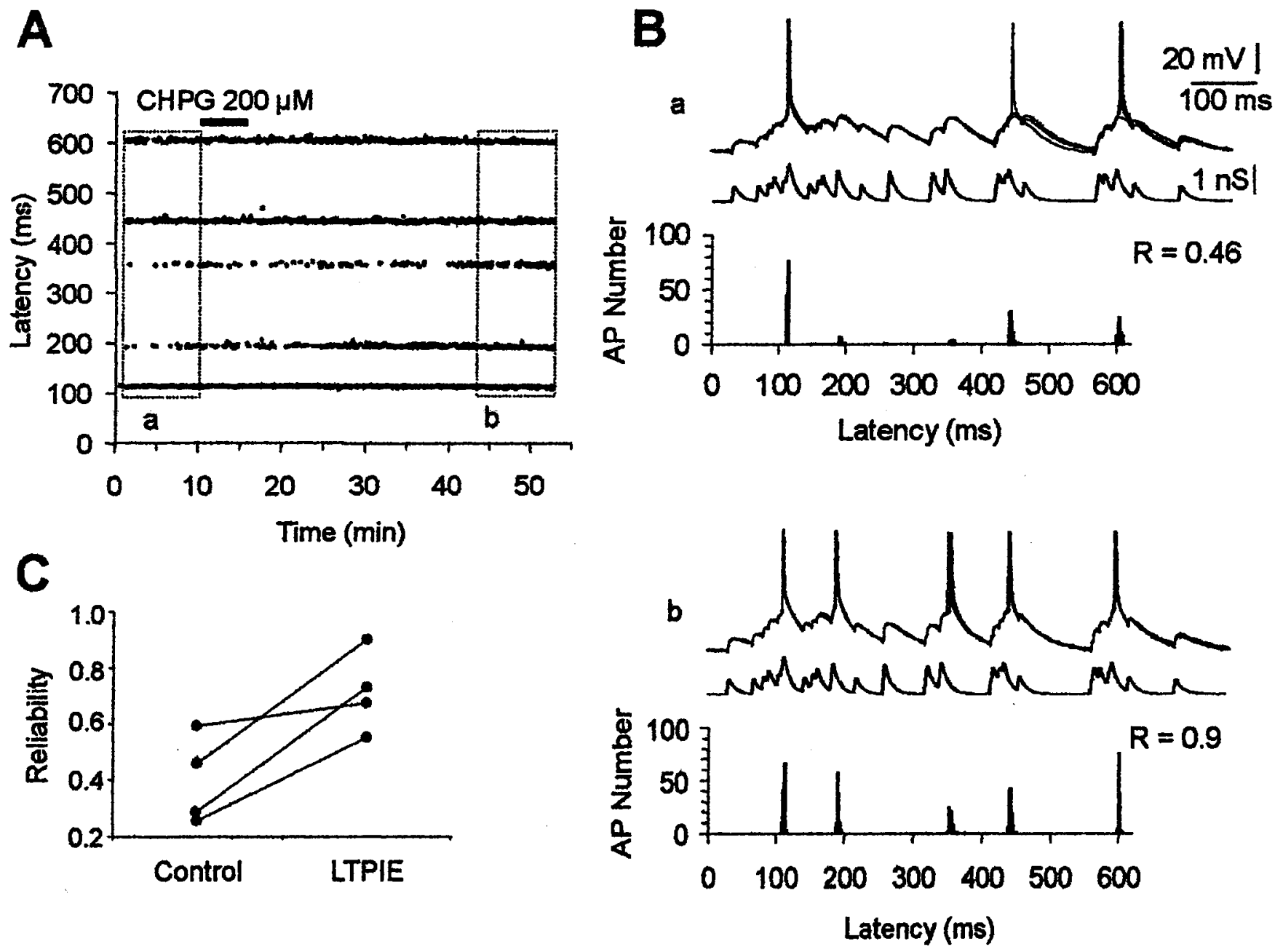

Figure 5. Enhanced reliability induced by mGluR5 activation. $A$, Temporal evolution of the raster of APs evoked by a barrage of EPSPs simulated with the dynamic-clamp technique (see middle traces in $B$ ) before and after LTP-IE induction by CHPG. The rectangles correspond to the period during which the reliability was calculated in $B$. B, Superimposed successive trials ( $n=3$ ) and histograms of spiking activity before $(a)$ and after $(b)$ induction of LTP-IE. Note the decreased jitter of the last APs. The reliability, determined by the number of APs in each peak of activity, was increased after LTP-IE ( $r=0.46 \mathrm{vs} r=0.9)$. C, Increased reliability was observed in all neurons tested $(n=4)$.

channels. In the presence of 40-100 nM apamin, neuronal excitability was enhanced, and the jitter of the second AP was significantly decreased $(\mathrm{SD}=19.9 \mathrm{msec}$ in control; $\mathrm{SD}=9.2 \mathrm{msec}$ in the presence of apamin; $n=8 p<0.05$ ) (Fig. $7 A, B$ ). We next tested the specific SK channel activator, EBIO (1 mM). In all experiments, EBIO decreased excitability, as shown previously (Pedarzani et al., 2001), but increased both the AHP amplitude and the jitter of the second $\mathrm{AP}(\mathrm{SD}=6.3 \mathrm{msec}$ in control; $\mathrm{SD}=$ $24.6 \mathrm{msec}$ in the presence of EBIO; $n=4 ; p<0.05$ ) (Fig. $7 C, D$ ). These results demonstrate that manipulations that affect $I_{\mathrm{AHP}}$, including LTP-IE, determine the precision of the spike train.

The modification in the jitter was associated with a change in the number and latency of evoked APs. For instance, in the presence of EBIO (0.5-1 mM), the latency of the second AP increased with the jitter. Similarly, early APs in the train usually exhibited less variability than late APs. To test whether the increased jitter was not caused solely by the change in excitability, we restored the spike number and the latency of the second AP to their initial levels (respectively, $95 \pm 3 \%, n=7$; median $=102 \pm 2 \%$ of the control, $n=7$ ) by slightly increasing the current pulse amplitude. Under these conditions, the jitter remained significantly increased $(\mathrm{SD}=6.0 \mathrm{msec}$ in control; $\mathrm{SD}=15.7 \mathrm{msec}$ in the presence of $0.5-1 \mathrm{~mm}$ EBIO with increased current intensity; $n=7$;
log-ANOVA; $p<0.05$ ) (Fig. $7 E, F$ ). These results indicate that the induced changes in general excitability and spike latency are not solely responsible for the jitter but rather the relative power of the MAHP current determines the variability of neuronal discharge.

mAHP determines the rate of depolarization and the firing precision

What is the biophysical determinant of the increased reliability of the spike train? During repetitive firing, the first APs display weak jitter compared with late APs (Mainen and Sejnowski, 1995). In parallel, the rate of membrane depolarization preceding the first spike is faster than that of the last APs (Azouz and Gray, 2000) (Fig. $8 A$ ). Thus persistent improvement in spike precision observed after LTP-IE might result from the acceleration in membrane depolarization as a result of the persistent depression of the mAHP current. We therefore measured the rate of depolarization preceding the second AP before and after induction of sLTP-IE. As expected, this rate was found to be significantly faster after sLTP-IE induced by $10 \mathrm{~Hz}$ tetanus $(109 \pm 4 \%$ of the control; $n=$ $6 ; p<0.01$ ) (Fig. $8 B$ ). In the presence of apamin $(40-100 \mu \mathrm{M})$, the rate of depolarization before the second AP was also found to be faster $(119 \pm 8 \% ; n=7 ; p<0.05)$ (Fig. $8 B)$. In contrast, it was 
slower in the presence of EBIO (82 $\pm 3 \%$; $n=4 ; p<0.05$ ) (Fig. $8 B$ ). These data indicate that tetanus-induced or pharmacological regulation of the apaminsensitive AHP current determines the rate of membrane depolarization.

We next examined the precision of firing when the rate of membrane depolarization was artificially controlled with current ramps. The temporal precision of the neuronal discharge was found to be more precise ( $\mathrm{SD}=58 \pm 10 \%$ of the control; $n=5$ ) when the rate of depolarization was slightly increased (rate $=129 \pm 5 \% ; n=$ 5) (Fig. $8 C, D$ ). These results indicate that he increased precision in discharge results from the rate of membrane depolarization that is determined by the relative power of the AHP. When apamin was applied, the jitter of the first AP elicited by a given ramp of current remained unchanged $(103 \pm 13 \% ; n=3$; data not shown). We conclude that after induction of mGluR-dependent LTP-IE, neurons will produce a reliable and temporally precise output message that results specifically from a change in the rate of depolarization.

\section{Discussion}

Our data show that mGluR activation induced a long-lasting (>60 min) increase in the spike number elicited by a current pulse or by a dendritic EPSP in layer $\mathrm{V}$ neurons. This potentiation was induced by synaptic stimulation of glutamatergic inputs when ionotropic receptors were blocked but was never observed when the tetanus was applied in the presence of MCPG. The pharmacological dissection of the induction mechanisms revealed that sLTP-IE and pLTP-IE resulted from the stimulation of mGluR5, which is expressed postsynaptically in layer $\mathrm{V}$ pyramidal neurons (Munoz et al., 1999). First, in the presence of the selective mGluR5 antagonist MPEP, the synaptic stimulation had no long-lasting effect on the intrinsic excitability of the neuron. In addition, pLTP-IE was induced by the selective mGluR5 agonist CHPG, but pLTP-IE was never observed when ACPD was applied in the presence of MPEP. sLTP-IE was completely occluded by pLTP-IE, indicating that they shared common expression mechanisms. These results are consistent with recent findings indicating that pharmacological stimulation of class I mGluRs induces a lasting potentiation of neuronal excitation in CA1 pyramidal neurons (Ireland and Abraham, 2002); however, our results indicate that mGluR1 does not significantly contribute to s/pLTP-IE induction in neocortical neurons. The increase in spike number was not the result of a regulation of miniature or spontaneous postsynaptic currents because AMPA receptors and $\mathrm{GABA}_{\mathrm{A}}$ receptors were blocked pharmacologically throughout experiments. We therefore conclude

A
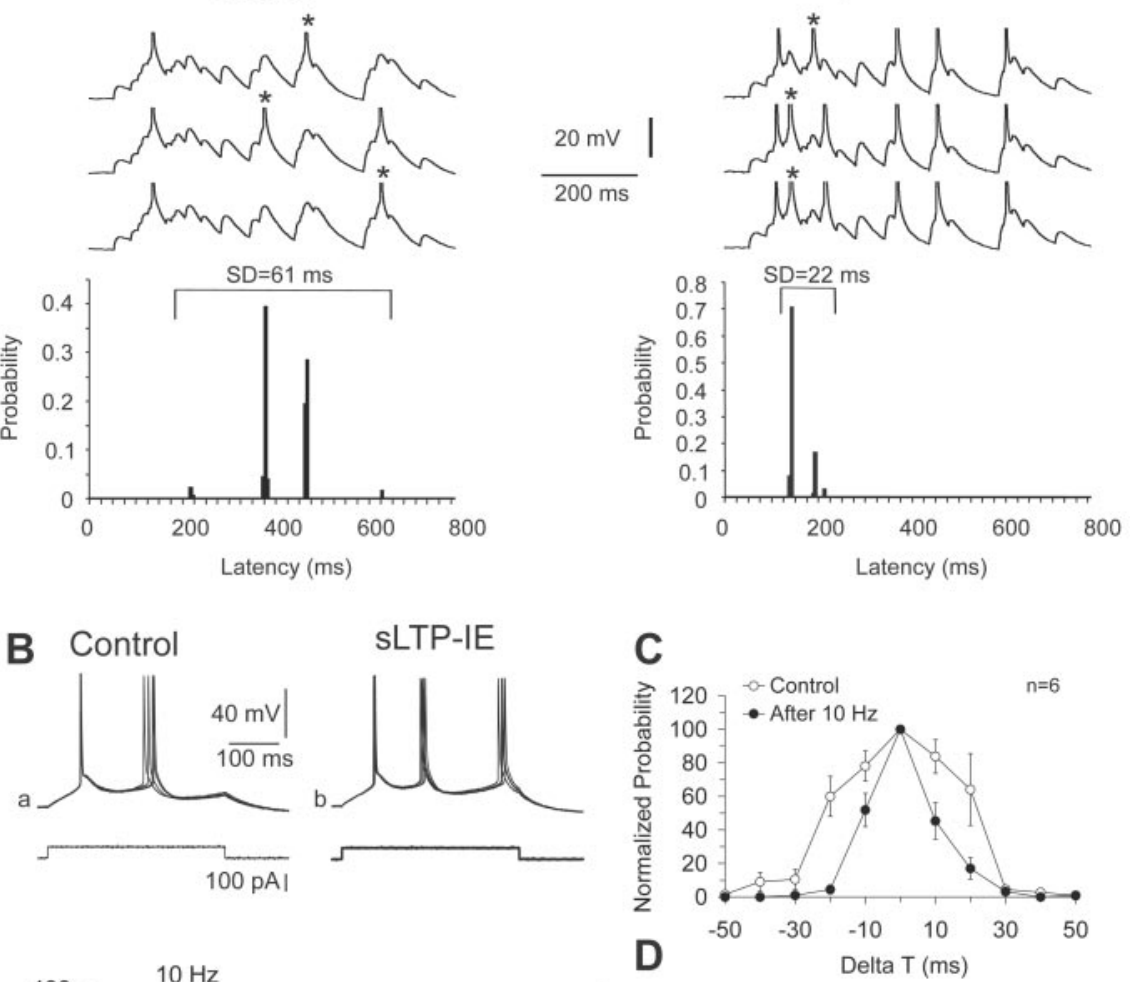

Figure 6. Increased temporal precision associated with LTP-IE. A, The jitter of the second spike (*) evoked by a barrage of simulated EPSPs was significantly reduced after induction of pLTP-IE. B, Tetanic stimulation $(10 \mathrm{~Hz})$ of glutamatergic inputs in the presence of kynurenate and picrotoxin enhanced the spike number but also induced a long-lasting reduction of the temporal jitter of spike discharge ( 3 superimposed traces). The jitter of the second AP was compared before and after LTP-IE induction in a time (black) and after (gray) the tetanus. C, D, Graphs showing the normalized distribution of the variations in latency of the second spike to the median. In all cases, empty circles represent the control distribution and solid circles represent the test distribution. The jitter of the second AP was reduced after LTP-IE induced by the $10 \mathrm{~Hz}$ tetanus $(C)(n=6)$ but not in experiments designed to assess temporal stability over $25 \min (D)(n=6)$.

that mGluR5 induced an increase in intrinsic excitability of layer $\mathrm{V}$ pyramidal neurons.

\section{Long-lasting reduction of $I_{\mathrm{AHP}}$}

We show here that both the mAHP induced by a burst of four APs and the $I_{\mathrm{AHP}}$ isolated pharmacologically were found to be depressed after induction of pLTP-IE with ACPD or CHPG. In particular, the presence of sodium channel blocker indicates that LTP-IE does not depend on activation of other neurons and therefore results from the direct postsynaptic stimulation of mGluRs. Under our recording conditions, the $s I_{\mathrm{AHP}}$ was blocked by $10 \mathrm{~mm}$ EGTA, as shown previously (Storm, 1987). The remaining AHP current was insensitive to TEA but was fully blocked by calcium-channel blockers, indicating that it was mediated by SK channels. In addition, sLTP-IE was occluded when 

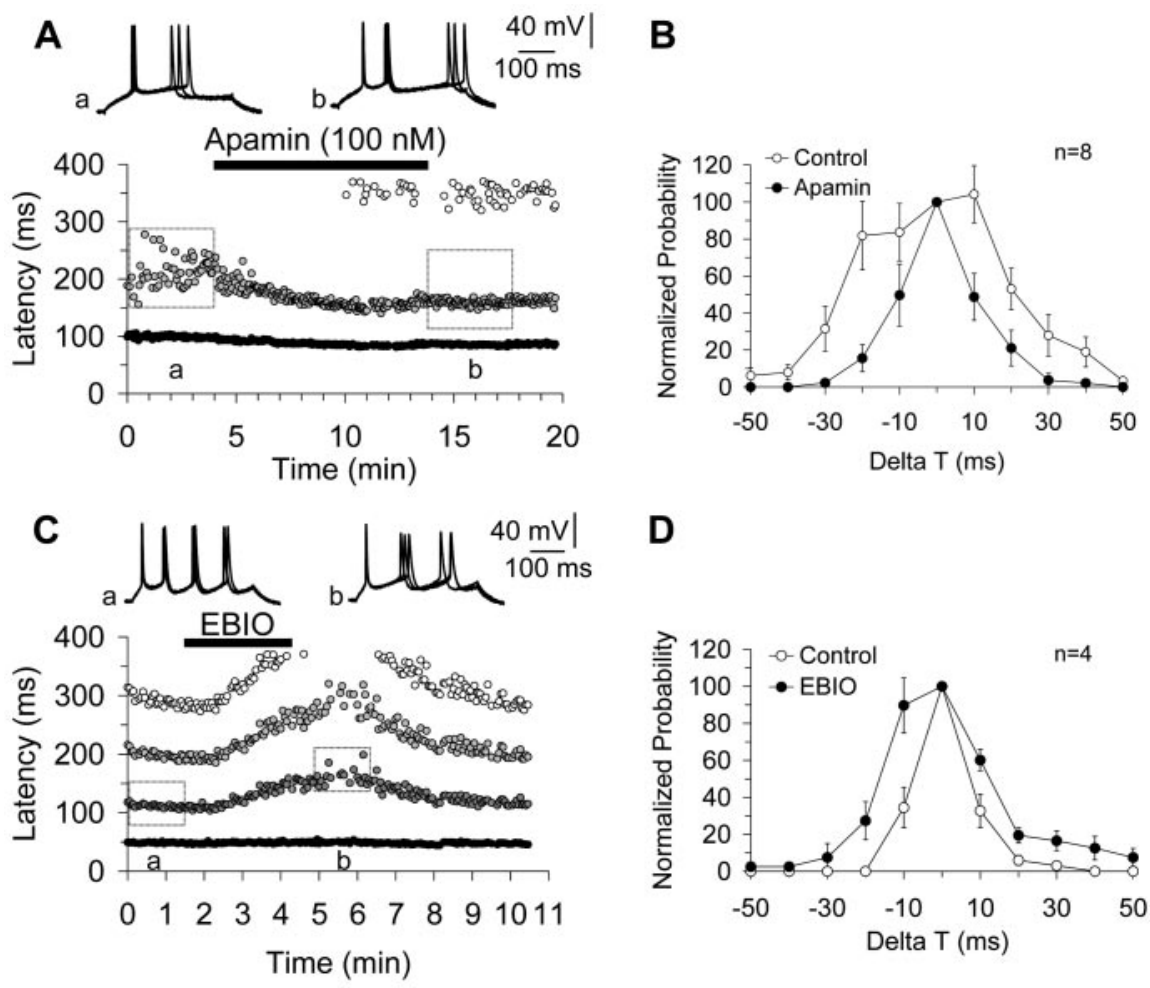

D
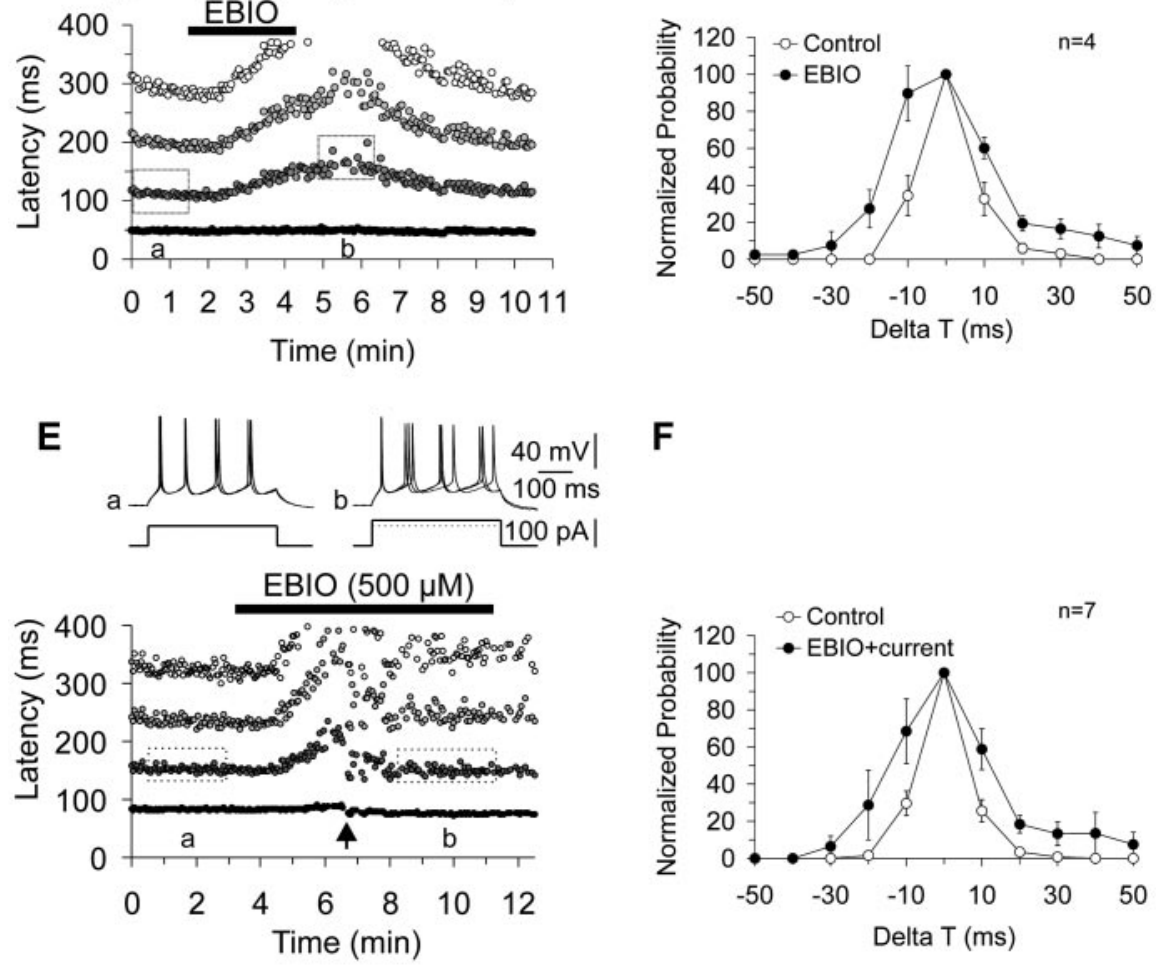

Figure 7. Modulation of the mAHP determines thejitter of the spike train. $A$, The SK channel blocker apamin increased neuronal excitability and decreased the jitter of the second AP. Dashed rectangles correspond to the time windows within which the jitter of the second spike was compared. $B$, Normalized distribution of the variations of the latency of the second spike to the median in control $(\bigcirc)$ and in the presence of 40-100 nm apamin $(O, n=8)$. C, The SK channel activator EBIO (1 mm) decreases neuronal excitability and increases the jitter in spike discharge. Dashed rectangles correspond to the time windows in which the jitter of the second spike was compared. D, Graph showing the normalized distribution of the variations of the latency of the second AP to the median in control $(O)$ and in the presence of $1 \mathrm{~mm} \operatorname{EBIO}(O, n=4)$. E, Relative independence of the jitter from the spike latency. Application of EBIO increased the latency and the jitter of the second AP. When the amplitude of the depolarizing current (vertical arrow) was slightly increased to restore the latency of the second AP, the jitter was still augmented. $F$, Normalized distribution of the variations of the latency of the second AP to the median in control $(\bigcirc)$ and in the presence of EBIO $(0.5-1 \mathrm{~mm})$ after compensation of the current amplitude $(, n=7)$.

the $10 \mathrm{~Hz}$ stimulation was applied in the presence of the SK channel blocker apamin. Thus the lasting reduction of the $I_{\mathrm{AHP}}$ current is sufficient to account for the increased excitability. This point remained unclear in a previous study in CA1 pyramidal neurons (Ireland and Abraham, 2002) because the very large reduction of the SAHP may have produced a small reduction of the $\mathrm{mAHP}$, as the consequence of the partial overlap of the two AHPs. Thus our data support a novel signaling pathway involving SK channels as a putative target of mGluR5. Additional experi- ments will be required to circumscribe more precisely the different steps of this pathway. The lack of depression of the voltage-gated calcium current indicates that the decrease in the $I_{\mathrm{AHP}}$ current might result from the regulation of the SK channels.

The downregulation of sAHP has been reported in CA1 pyramidal neurons after pharmacological stimulation of mGluRs (Ireland and Abraham, 2002). What is the role of $s I_{\mathrm{AHP}}$ in $s L T P$-IE in our experiments? When intracellular calcium was weakly buffered with $0.5 \mathrm{~mm}$ EGTA and in the presence of apamin, a small but significant sLTP-IE was reliably induced by the $10 \mathrm{~Hz}$ stimulation. Because $s I_{\mathrm{AHP}}$ was not blocked in these experiments, one cannot exclude its contribution to sLTP-IE in layer V neocortical neurons; however, this hypothesis will need further investigation. Thus, in addition to SK channels, other currents such as $\mathrm{sI}_{\mathrm{AHP}}$ may also participate in the expression of SLTP-IE.

The depression of $I_{\mathrm{AHP}}$ accounts for the increased spike number elicited by a current pulse but also for the enhanced EPSPspike coupling. Indeed, it has been established recently that $\mathrm{s} I_{\mathrm{AHP}}$ attenuates subthreshold EPSPs (Lancaster et al., 2001), and it is therefore possible that similar mechanisms involve SK channels. Several forms of activity-dependent increases in intrinsic excitability are also mediated by a downregulation of the AHP current. A lasting reduction of the AHP has been reported in hippocampal and neocortical neurons after classical and operant conditioning (Disterhoft et al., 1986; Saar et al., 1998). Lasting reduction of $s I_{\mathrm{AHP}}$ has also been characterized in CA1 pyramidal cells after pharmacological stimulation of mGluRs (Cohen et al., 1999; Ireland and Abraham, 2002) or kainate receptors (Melyan et al., 2002). Other $\mathrm{K}^{+}$currents have been shown to be regulated by neuronal activity (Desai et al., 1999). Our data provide the first evidence for a long-lasting decrease of $I_{\mathrm{AHP}}$ induced by synaptic activity. This regulation of $I_{\mathrm{AHP}}$, however, does not preclude a contribution of other voltage-gated conductances to this effect.

\section{Potentiation of the neuronal input-output function}

Hippocampal EPSP-spike potentiation has been reported after mGluR stimulation (Breakwell et al., 1996; Cohen et al., 1999), but the contribution of increased excitability was not clearly demonstrated in these studies. In our experiments, the inputoutput function was facilitated for both somatic current injection and evoked dendritic EPSPs, and mGluR5-induced LTP-IE effectively enhanced EPSP-spike coupling. Thus, LTP-IE facilitates 
A

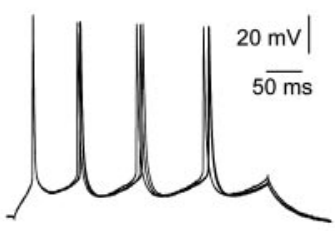

B

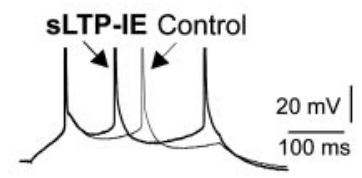

Control EBIO

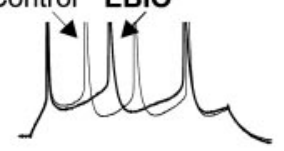

C
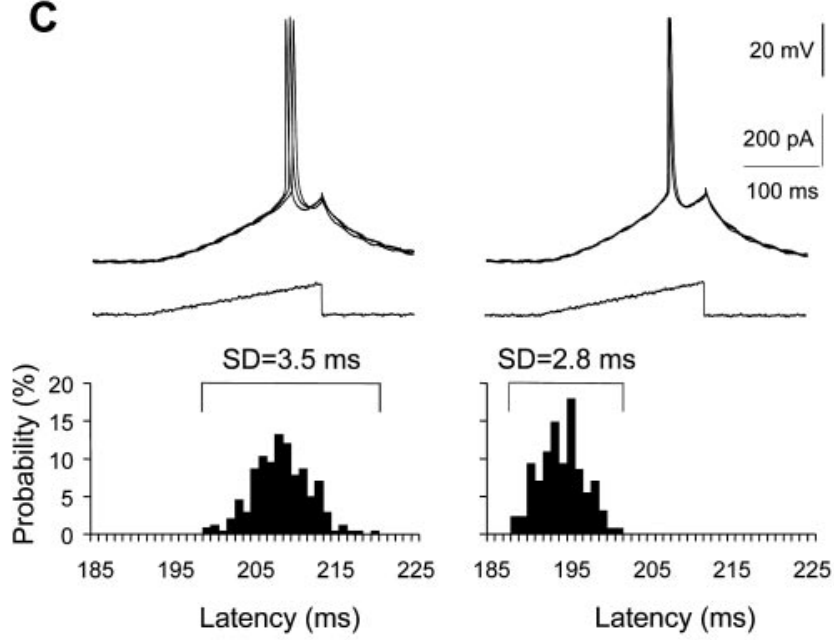

Apamin Control
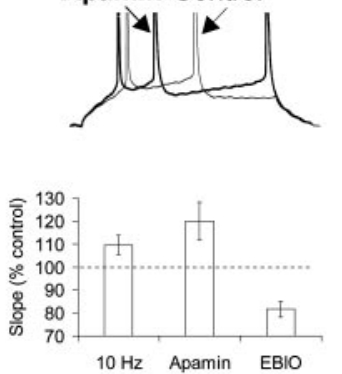

$\mathrm{SD}=2.8 \mathrm{~ms}$

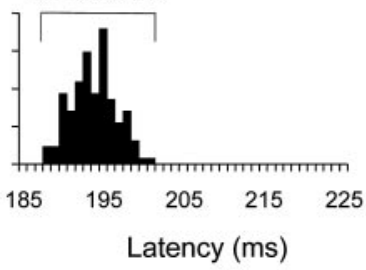

D

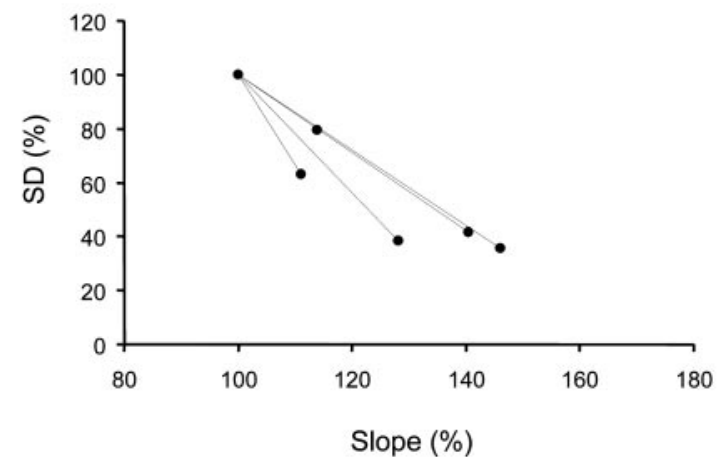

Figure 8. mAHP determines the rate of membrane depolarization and spike precision. $A$, Comparison of the rate of depolarization before each AP of the train. Left, Superimposition of three consecutive trains of spikes evoked by a suprathreshold current pulse. The precision of each spike decreased along the train. Right, Expansion of the trace before the second spike (2) and third spike (3). The rate of depolarization of the membrane was measured between two cursors ( -15 to -10 msec before each AP). Note the difference between the rate of depolarization before spike 2 and spike 3. $B$, The rate of membrane depolarization before the second AP was measured before and after induction of LTP-IE and application of $40-100 \mathrm{~nm}$ apamin and 1 mм EBIO. LTP-IE and apamin induced a significant increase of the rate of depolarization, whereas EBIO decreased this rate. C, The firing precision of the neuron was assessed with slow and fast rates of depolarization induced by current ramps. The voltage slope imposed by the ramp corresponded to the depolarizing slopes preceding the second APs in SLTP-IE experiments (range, $0.17-0.24 \mathrm{mV} / \mathrm{msec}$ ). Firing became more precise when the rate of depolarization the spread of excitation in the cortical network and may contribute, with lasting synaptic modifications, to the formation of the cortical engram.

\section{Specificity of the enhanced excitability}

In contrast to NMDAR-dependent intrinsic plasticity (Daoudal et al., 2002), mGluR-dependent LTP-IE does not appear to be input specific. LTP-IE could be induced by synaptic stimulation in the dendrites and was revealed by current injection in the cell body; however, a gradient of excitability might exist between the dendrites and the soma because of the dendritic location of AHP channels (Sailer et al., 2002). Thus, in addition to its contribution in the spread of cortical activity, LTP-IE could also set a largescale time window of several tens of minutes to hours in which activity-dependent synaptic modifications are more likely to occur. This view is supported by the finding that block of $s I_{\mathrm{AHP}}$ enhances LTP induction in the hippocampus (Sah and Bekkers, 1996) and that activation of mGluR also favors the subsequent induction of LTP (Cohen et al., 1999). It is expected that similar mechanisms of metaplasticity may also occur in neocortical neurons.

The probability of LTP-IE induction was found to be higher when postsynaptic spikes were delivered during the stimulation of mGluRs. The associative nature of mGluR-dependent LTP-IE suggests that active but not silent neurons will be preferentially potentiated during elevation of the glutamate concentration. This property may result from the synergistic release of $\mathrm{Ca}^{2+}$ from internal stores evoked by the mGluR activation paired with backpropagating action potentials (Nakamura et al., 1999). In fact, this view is further supported by the $\mathrm{Ca}^{2+}$ sensitivity of several proteins involved in the signaling pathway of mGluR5.

\section{Long-lasting enhancement of reliability and temporal precision}

The temporal precision of the AP in central neurons has synaptic (Pouille and Scanziani, 2001) and nonsynaptic determinants (Schoppa and Westbrook, 1999; Fricker and Miles, 2001). Longlasting, activity-dependent modification in the temporal structure of neuronal discharge has not been reported previously. Our data show that activation of glutamatergic synapses not only increases the input-output function of the neuron but also enhances the temporal fidelity of its output message.

The reliability of layer $\mathrm{V}$ pyramidal neurons was increased after LTP-IE induction. This was seen with both dendritically evoked and simulated EPSPs. The use of the dynamic-clamp technique allowed us to minimize the fluctuations in EPSP amplitude resulting from probabilistic presynaptic release. The reliability of late APs was enhanced after mGluR5 stimulation as a result of the depression of $I_{\mathrm{AHP}}$.

In parallel, our data strongly suggest that the temporal precision of the spike train evoked by a barrage of simulated EPSPs or by a current pulse is enhanced after the stimulation of a glutamatergic pathway or the stimulation of mGluR5. Again, this increase in temporal precision was not caused by synaptic activity because ionotropic receptors were blocked pharmacologically. Rather, this enhanced temporal precision resulted from the long-term

$\leftarrow$

increased (left column, $0.186 \mathrm{mV} / \mathrm{msec}$, SD $=3.5 \mathrm{msec}, n=242$ trials; right column, 0.212 $\mathrm{mV} / \mathrm{msec} \mathrm{SD}=2.8 \mathrm{msec}, n=119$ trials). $D$, Improvement of the precision of the discharge (decrease in SD) with moderate increases in the slope of the voltage ramp ( $n=5$ neurons). 
regulation of postsynaptic currents that govern the neuronal discharge.

The mechanisms responsible for the temporal precision of firing in central neurons have not yet been elucidated. Here we show that jitter of the second spike was decreased by the SK channel blocker apamin but was increased by the SK channel activator EBIO. The biophysical mechanisms responsible for the decreased jitter are independent of spike latency and excitability. Indeed, in the EBIO experiment the increase in spike latency and the decrease in spike number could be compensated by current injection but instead jitter remained significantly enhanced, suggesting that the power of the outward current largely determines the temporal variability of the action potentials. Thus, the improved precision of firing is not simply an epiphenomenon of increased excitability. Furthermore, we demonstrate that the precision is imposed by the rate of membrane depolarization preceding each spike. After induction of LTP-IE or in the presence of apamin, this rate was found to be faster, and temporal precision was increased. Conversely, in the presence of EBIO the rate decreased and jitter increased. Thus, after induction of LTP-IE, the faster rate of depolarization that results from a lasting depression of $I_{\mathrm{AHP}}$ will increase the temporal precision of the output message.

What are the consequences of long-lasting modifications in the temporal precision and reliability on the dynamics of the cortical network? The answer to this question is pending, but improved fidelity in spike discharge is expected to have dramatic consequences on neuronal coding. Computational theories indicate that neuronal codes based on spike timing can make more efficient use of the capacity of neural connections than those that rely simply on the average rate of firing (Abeles, 1991; Singer, 1999). Thus the activity-dependent modifications in temporal precision of the spike train that we report here might contribute to the formation of internal representations using neuronal codes based on spike timing. Additional experimental and theoretical studies will be required to test this hypothesis. In addition, longlasting modification of spiking variability may also have important consequences on subsequent induction of synaptic plasticity that depends on coincidence detection (Bi and Poo, 1998; Debanne et al., 1998). For instance, it will be important to evaluate the role of improved reliability in the spike train on the subsequent induction of spike timing-dependent plasticity by increasing the level of coactivation. In particular, the reduction in spike jitter could set the amplitude and the polarity of the induced plasticity (Froemke and Dan, 2002). It will be important to determine whether long-lasting, activity-dependent enhancement of spike timing also occurs in vivo.

\section{References}

Abbott LF, Nelson SB (2000) Synaptic plasticity: taming the beast. Nat Neurosci 3:1178-1183

Abeles M (1991) Corticonics: neural circuits of the cerebral cortex. Cambridge, UK: Cambridge UP.

Aizenman CD, Linden DJ (2000) Rapid, synaptically driven increases in the intrinsic excitability of cerebellar deep nuclear neurons. Nat Neurosci 3:109-111.

Armano S, Rossi P, Taglietti V, D’Angelo E (2000) Long-term potentiation of intrinsic excitability at the mossy fiber-granule cell synapse of rat cerebellum. J Neurosci 20:5208-5216.

Azouz R, Gray C (2000) Dynamic spike threshold reveals a mechanism for synaptic coincidence detection in cortical neurons in vivo. Proc Natl Acad Sci USA 97:8110-8115.

Bi GQ, Poo MM (1998) Synaptic modifications in cultured hippocampal neurons: dependence on spike-timing, synaptic strength, and postsynaptic cell type. J Neurosci 18:10464-10472.
Bliss TVP, Collingridge GL (1993) A synaptic model of memory: long-term potentiation in the hippocampus. Nature 361:31-39.

Bortolotto ZA, Bashir ZI, Davies CH, Collingridge GL (1994) A molecular switch activated by metabotropic glutamate receptors regulates induction of long-term potentiation. Nature 368:740-743.

Breakwell NA, Rowan MJ, Anwyl R (1996) Metabotropic glutamate receptor dependent EPSP and EPSP-spike potentiation in area CA1 of the submerged rat hippocampal slice. J Neurophysiol 76:3126-3135.

Charpak S, Gähwiler BH, Do KQ, Knöpfel T (1990) Potassium conductances in hippocampal neurons blocked by excitatory amino-acid transmitters. Nature 347:765-767.

Cohen A, Coussens CM, Raymond CR, Abraham WC (1999) Long-lasting increase in cellular excitability associated with the priming of LTP induction in rat hippocampus. J Neurophysiol 82:3139-3148.

Daoudal G, Hanada Y, Debanne D (2002) Bi-directional plasticity of EPSPspike coupling in CA1 hippocampal pyramidal neurons. Proc Natl Acad Sci USA 99:14512-14517.

Debanne D, Gähwiler BH, Thompson SM (1998) Long-term synaptic plasticity between pairs of individual CA3 pyramidal cells in rat hippocampal slice cultures. J Physiol (Lond) 507:237-247.

Desai NS, Rutherford LC, Turrigiano GG (1999) Plasticity of the intrinsic excitability of cortical pyramidal neurons. Nat Neurosci 2:515-520.

Disterhoft JF, Coulter DA, Alkon DL (1986) Conditioning-specific membrane changes of rabbit hippocampal neurons measured in vitro. Proc Natl Acad Sci USA 83:2733-2737.

Fricker D, Miles R (2001) EPSP amplification and the precision of spike timing in hippocampal neurons. Neuron 28:559-569.

Froemke RC, Dan Y (2002) Spike-timing-dependent synaptic modification induced by natural spike trains. Nature 416:433-438.

Ganguly K, Kiss L, Poo M (2000) Enhancement of presynaptic neuronal excitability by correlated presynaptic and postsynaptic spiking. Nat Neurosci 3:1018-1026.

Gasparini F, Lingerhöhl K, Stoehr N, Flor PJ, Heinrich M, Vranesic I, Biollaz M, Allgeier H, Heckendorn R, Urwyler S, Varney MA, Johnson EC, Hess SD, Rao SP, Sacaan AI, Santori EM, Veliçelebi G, Kuhn R (1999) 2-methyl-6-(phenylethyl)-pyridine (MPEP), a potent, selective and systematically active mGluR5 receptor antagonist. Neuropharmacology 38:1493-1503.

Harsch A, Robinson HPC (2000) Postsynaptic variability of firing in rat cortical neurons: the roles of input synchronization and synaptic NMDA receptor conductance. J Neurosci 20:6181-6192.

Ireland DR, Abraham WC (2002) Group I mGluRs increase excitability of hippocampal CA1 pyramidal neurons by a PLC-independent mechanism. J Neurophysiol 88:107-116.

Lancaster B, Hu H, Ramakers GMJ, Storm JF (2001) Interaction between synaptic excitation and slow afterhyperpolarization current in rat hippocampal pyramidal cells. J Physiol (Lond) 536:809-823.

Magee JC, Johnston D (1997) A synaptically-controlled, associative signal for Hebbian plasticity in hippocampal neurons. Science 275:209-213.

Mainen ZF, Sejnowski TJ (1995) Reliability of spike timing in neocortical neurons. Science 268:1503-1506.

Mannaioni G, Marino MJ, Valenti O, Traynelis SF, Conn PJ (2001) Metabotropic glutamate receptors 1 and 5 differentially regulate CA1 pyramidal cell function. J Neurosci 21:5925-5934.

Markram H, Lübke J, Frotscher M, Sakmann B (1997) Regulation of synaptic efficacy by coincidence of postsynaptic APs and EPSPs. Science 275:213-215.

Melyan Z, Wheal HV, Lancaster B (2002) Metabotropic-mediated kainate receptor regulation of $\mathrm{I}_{\mathrm{sAHP}}$ and excitability in pyramidal cells. Neuron 34:107-114.

Moyer Jr JR, Thompson LT, Disterhoft JF (1996) Trace eyeblink conditioning increases CA1 excitability in a transient and learning-specific manner. J Neurosci 16:5536-5546.

Munoz A, Liu XB, Jones EG (1999) Development of metabotropic glutamate receptors from trigeminal nuclei to barrel cortex in postnatal mouse. J Comp Neurol 409:549-566.

Nakamura T, Barbara JG, Nakamura K, Ross WN (1999) Synergistic release of $\mathrm{Ca}^{2+}$ from IP3-sensitive stores evoked by synaptic activation of mGluRs paired with backpropagating action potentials. Neuron 24:727-737. 
Pedarzani P, Mosbacher J, Rivard A, Cingolani LA, Oliver D, Stocker M, Adelman JP, Fakler B (2001) Control of electrical activity in central neurons by modulating the gating of small conductance $\mathrm{Ca}^{2+}$-activated $\mathrm{K}^{+}$channels. J Biol Chem 276:9762-9769.

Pouille F, Scanziani M (2001) Enforcement of temporal fidelity in pyramidal cells by somatic feed-forward inhibition. Science 293:1159-1163.

Saar D, Grossman Y, Barkai E (1998) Reduced after-hyperpolarization in rat piriform cortex pyramidal neurons is associated with increased learning capability during operant conditioning. Eur J Neurosci 10:1518-1523.

Sah P, Bekkers JM (1996) Apical dendrite location of slow afterhyperpolarization current in hippocampal pyramidal neurons: implications for the integration of long-term potentiation. J Neurosci 16:4537-4542.

Sailer CA, Hu H, Kaufmann WA, Trieb M, Schwarzer C, Storm JF, Knaus HG (2002) Regional differences in distribution and functional expression of small-conductance $\mathrm{Ca}^{2+}$-activated $\mathrm{K}^{+}$channels in rat brain. J Neurosci 22:9698-9707.
Schoppa NE, Westbrook GL (1999) Regulation of synaptic timing in the olfactory bulb by an A-type potassium current. Nat Neurosci 2:1106-1113.

Sharp AA, O’Neil M, Abbott LF, Marder E (1993) Dynamic clamp: computergenerated conductances in real neurons. J Neurophysiol 69:992-995.

Singer W (1999) Neuronal synchrony: a versatile code for the definition of relations? Neuron 24:49-65.

Sourdet V, Debanne D (1999) The role of dendritic filtering in associative long-term synaptic plasticity. Learn Mem 6:422-447.

Stocker M, Pedarzani P (2000) Differential distribution of three $\mathrm{Ca}^{2+}$ activated $\mathrm{K}^{+}$channel subunits, SK1, SK2 and SK3 in the adult rat central nervous system. Mol Cell Neurosci 15:476-493.

Storm J (1987) Intracellular injection of a $\mathrm{Ca}^{2+}$ chelator inhibits spike repolarization in hippocampal neurons. Brain Res 435:387-392.

Velumian AA, Zhang L, Pennefather P, Carlen PL (1997) Reversible inhibition of $\mathrm{I}_{\mathrm{K}}, \mathrm{I}_{\mathrm{AHP}}, \mathrm{I}_{\mathrm{h}}$ and $\mathrm{I}_{\mathrm{Ca}}$ currents by internally applied gluconate in rat hippocampal pyramidal neurones. Pflügers Arch 433:343-350. 